Available online at http://jurnal.goretanpena.com/index.php/JSSR

\title{
RANCANG BANGUN DAN IMPLEMENTASI SIADES PADA DESA PERJUANGAN KAB. BATU BARA
}

\author{
Febri Dristyan $^{1}$, Koko Priyanto ${ }^{2}$, Suci Andriyani ${ }^{3}$ \\ STMIK Royal, Kisaran \\ e-mail: '1dristyan@gmail.com
}

\begin{abstract}
Perjuangan Village in terms of managing population administration is still manual, even though population administration is very important in government. With the progress of science and technology today, the authors make research on the village administration information system (SIADES) that can overcome these problems. In designing the system using the RAD (Rapid Application Development) method, assisted by the Visual Studio programming language and using the MySQL database.
\end{abstract}

Keywords: Design and Build, UML, Village Administration Information System

\begin{abstract}
Abstrak: Desa Perjuangan dalam hal pengurusan administrasi kependudukan masih bersifat manual, padahal administrasi kependudukan sangatlah penting dalam pemerintahan. Dengan Kemajuan ilmu pengetahuan serta teknologi saat ini maka penulis membuat penelitian mengenai sistem informasi administrasi desa (SIADES) yang dapat mengatasi permasalahan tersebut. Dalam perancangan sistem nya menggunakan metode RAD (Rapid Application Development), dibantu dengan Bahasa pemograman Visual Studio dan menggunakan database MySQL.
\end{abstract}

Kata kunci: Rancang Bangun, UML, Sistem Informasi Administrasi Desa

\section{PENDAHULUAN}

Administrasi Kependudukan bagian dari sistem administrasi negara dimana memiliki fungsi yang sangat penting dalam pemerintahan dalam hal pengelolaan data kependudukan (Amalia, 2017). Pengelolaan data penduduk merupakan tanggung jawab Pemerintah Kabupaten maupun Pemerintah Kota dimana dalam pelaksanaannya diawali dari Desa atau Kelurahan. Dalam pelayanan pengurusan administrasi baik itu pendaftaran penduduk maupun pembuatan surat keterangan yang laiinya perlu dilakukan dengan baik dan cepat agar penduduk merasakan pelayanan yang memuaskan.

Pada Desa Perjuangan yang terletak di Kabupaten Batu Bara Provinsi Sumatera Utara terdapat beberapa pelayanan administrasi kependudukan yang dilayani di antaranya ialah administrasi pembuatan surat pengantar kartu tanda penduduk (KTP), kartu keluarga $(\mathrm{KK})$, surat keterangan pindah kependudukan, surat kelahiran dan lain sebagainya. Selama ini pelayanan adminstrasi pada Desa Perjuangan belum sepenuhnya secara komputerisasi, masih menggunakan pembukuan atau arsip-arsip untuk mencatat setiap layanan administrasi yang dilakukan masyarakat (Khaerunnisa, 2020), sehingga seringkali terjadi kesalahan bahkan ada arsip yang hilang atau rusak..

Dengan adanya permasalahan tersebut menimbulkan tidak efisiennya waktu yang digunakan untuk memproses pelayanan administrasi kependudukan dalam hal pencarian data penduduk sampai terbitnya surat pengantar yang diminta oleh masyarakat. Disinilah dibutuhkan peran dari teknologi sistem informasi untuk membantu kinerja dari 
Available online at http://jurnal.goretanpena.com/index.php/JSSR

suatu instansi / perusahaan / organisasi (Aulia, 2019) \& (Rizaldi, 2020)

Sistem Informasi yang akan dirancang adalah Sistem Informasi Administrasi Desa (SIADES). Dimana didalam sistem informasi ini nantinya akan membantu perangkat desa dalam hal pembuatan atau penerbitan surat administrasi kependudukan

\section{METODE}

Dalam mengembangkan SIADES untuk keperluan administrasi desa dilakukan dengan pendekatan metode Rapid Application Development (Sikumbang, 2020).

\section{(RAD)}

Rapid Application Development pengembangan serta perangkat-perangkat lunak.

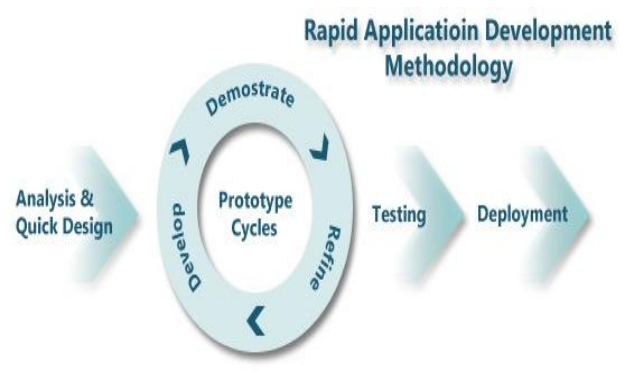

Gambar 1. Model RAD

Model RAD ini memiliki tiga fase tahapan dalam pengembangan aplikasi (Mandang,2020).

1. Requiretment Planning, dalam tahap ini diketahui apa saja yang menjadi kebutuhan dalam sistem. Dengan mengidentifikasi kebutuhan informasi dan masalah yang dihadapi agar tujuan , batasan-batasan sistem, kendala dan juga alternatif pemecahan masalah dapat ditentukan.

2. Design Workshop, pada tahapan ini membuat desain proses bisnis dan desain pemrograman untuk data-data yang telah didapatkan dan dimodelkan dalam arsitektur sistem informasi. Tools yang biasa dipakai dalam pemodelan sistem ialah Unified Modeling Language (UML) (Christina,2021).

3. Implementation, di dalam tahap terakhir ini sistem di implementasikan dari coding ke dalam bentuk yang di mengerti oleh mesin yang di wujudkan dalam bentuk program atau unit program.

\section{HASIL DAN PEMBAHASAN}

Pada tahap pertama dari model RAD kita rancang kebutuhan dari sistem SIADES ini menggunakan aliran sistem informasi,yang di gambarkan pada gambar 2 aliran sistem informasi yang sedang berjalan.

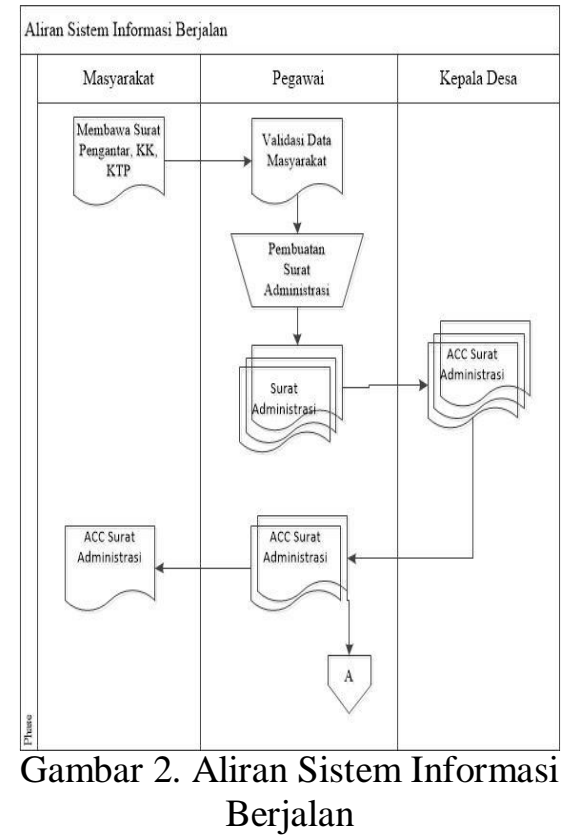

Pada Tahapan kedua dilakukan desain dari proses bisnis dan desain pemograman. Pemodelan proses bisnis dibantu dengan Unified Modeling Language(UML). Dalam pembuatan UML pertama kali dirancang ialah Usecase Diagram yang menggambarkan hubungan antara actor dengan sistem 
Available online at http://jurnal.goretanpena.com/index.php/JSSR

seperti yang terlihat pada Gambar.3 disana bisa dilihat kegiatan dari admin sistem (pegawai balai desa) mengelola data penduduk, mengelola data surat dan mengelola penerbitan surat. Dan masyarakat meminta surat administrasi.

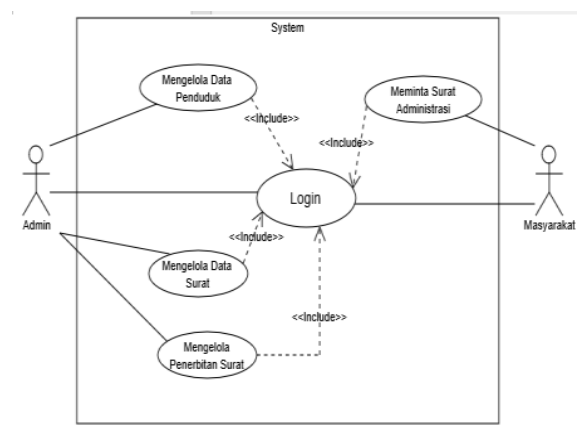

Gambar 3. Usecase Diagram

Pada tahap terakhir dari metode RAD ini implementasi dari rancangan yang telah di rancang UML di terjemahkan ke dalam bahasa pemograman. Sebelum di terjemahkan kedalam bahasa pemograman di rancang terlebih dahulu basis data dari SIADES ini. Adapun perancangan basis data nya sebagai berikut nama database : db_administrasi_desa, fungsi menyimpan seluruh table dalam database.

Table 1. Tabel Database

\begin{tabular}{|c|c|c|}
\hline No & Nama Tabel & Fungsi \\
\hline 1 & tbl_penduduk & $\begin{array}{l}\text { Menyimpan } \\
\text { data } \\
\text { penduduk }\end{array}$ \\
\hline 2 & tbl_siusaha & $\begin{array}{l}\text { Menyimpan } \\
\text { data surat } \\
\text { izin usaha }\end{array}$ \\
\hline 3 & tbl_spindah & $\begin{array}{l}\text { Menyimpan } \\
\text { data surat } \\
\text { keterangan } \\
\text { pindah }\end{array}$ \\
\hline 4 & tbl_spernyataan & $\begin{array}{l}\text { Menyimpan } \\
\text { data surat } \\
\text { pernyataan }\end{array}$ \\
\hline & tbl_skelahiran & $\begin{array}{l}\text { Menyimpan } \\
\text { data surat } \\
\text { keterangan } \\
\text { lahir }\end{array}$ \\
\hline
\end{tabular}

Selesai dengan pembuatan database dilanjutkan kepada desain antar muka.

Tampilan menu Login

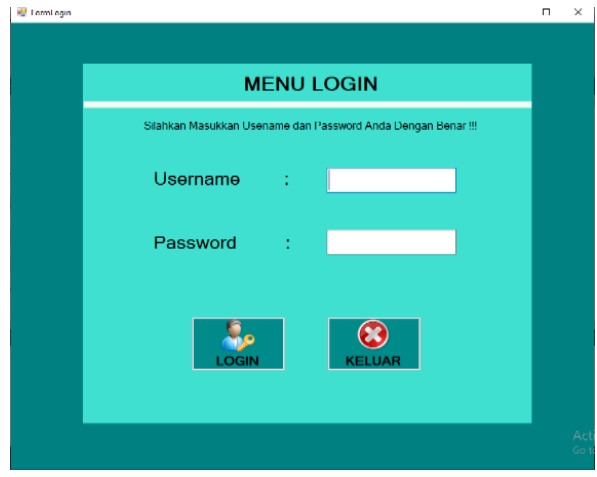

Gambar 4. Menu Login

Tampilan Menu Utama

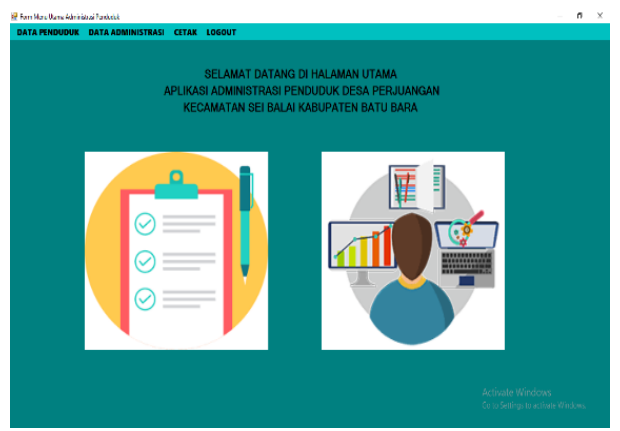

Gambar 5. Menu Utama

Tampilan Menu Data Penduduk

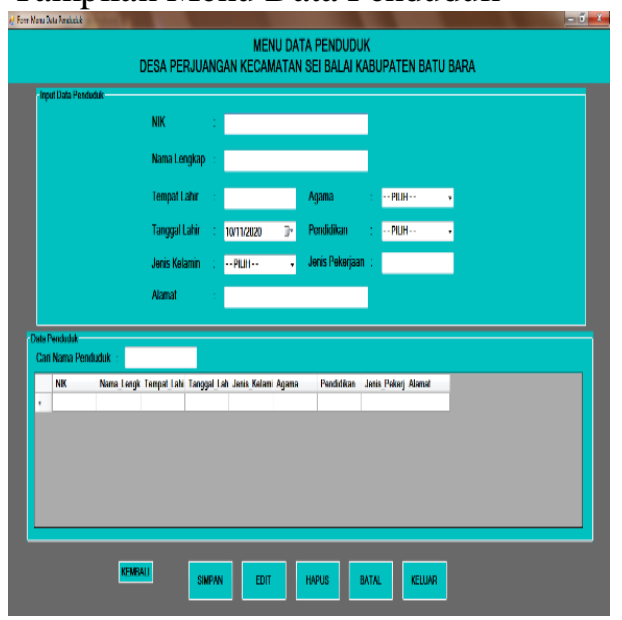

Gambar 6. Menu Data Penduduk 
Available online at http://jurnal.goretanpena.com/index.php/JSSR

Tampilan Menu Surat Izin Usaha

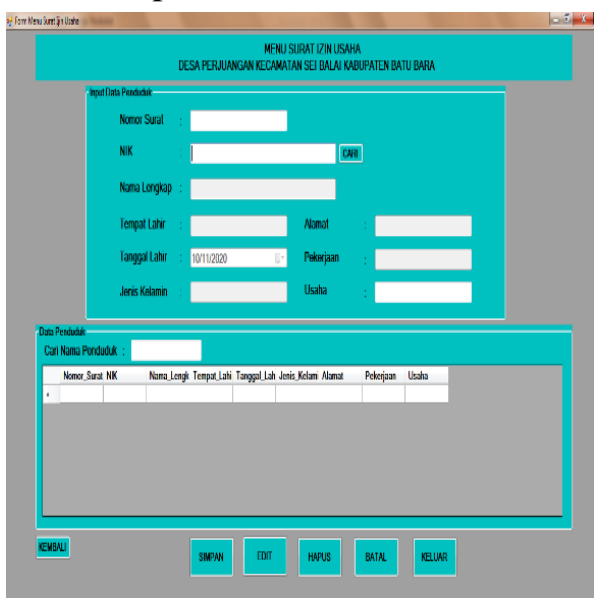

Gambar 7. Menu Surat Izin Usaha

Tampilan Menu Surat Kelahiran

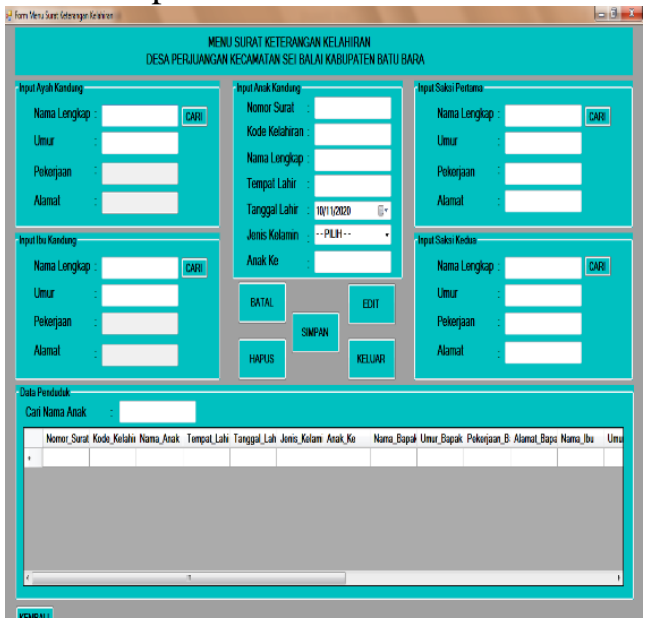

Gambar 8. Menu Surat Kelahiran

Tampilan Menu Surat Pindah

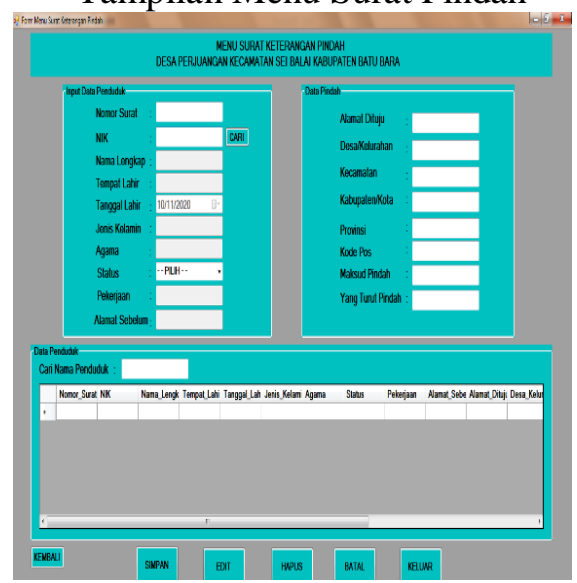

Gambar 9. Menu Surat Pindah
Tampilan Menu Surat Pernyataan

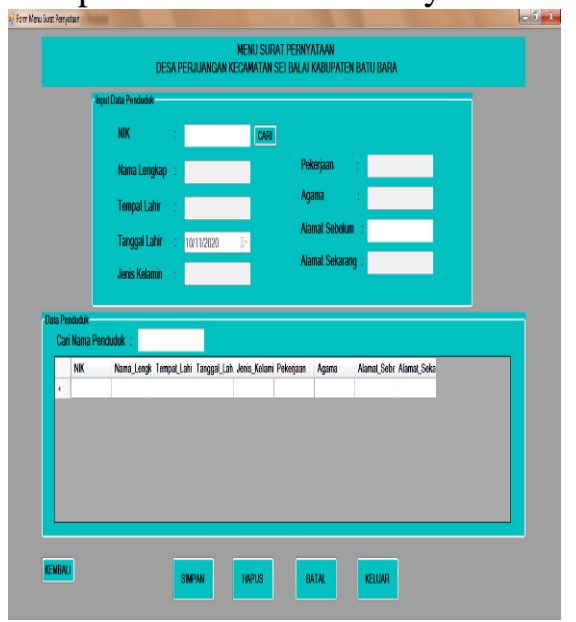

Gambar 10. Menu Surat Pernyataan

\section{SIMPULAN}

Biasanya untuk membuat surat izin usaha seorang masyarakat harus meminta surat pengantar dulu dari Kepala lingkungan baru bisa ke balai desa. Dengan adanya aplikasi SIADES (Sistem Informasi Administrasi Desa) sangat membantu dalam pembuatan surat administrasi untuk masyarakat desa secara cepat tepat dan efisien. Serta data masyarakat berupa No KTP dan No KK yang sudah di simpan dalam database SIADES memudahkan masyarakat untuk meminta atau membuat surat-surat administrasi yang di inginkan

\section{DAFTAR PUSTAKA}

Y. S. Endang Amalia, "Perancangan Sistem Informasi Administrasi Kependudukan Sebagai Pengembangan Egovernment," Pros. Semin. Ilmu Komput. dan Teknol. Inf., vol. 2, no. 1, p. 82, 2017.

N. Khaerunnisa and Nofiyati, "WebBased Administration Population Service Information System Case Study of Sidakangen Village , 
Available online at http://jurnal.goretanpena.com/index.php/JSSR

Purbalingga," J. Tek. Inform., vol. 1, no. 1, pp. 25-32, 2020.

F. D. Romy Aulia, Mardalius Mardalius, "Peningkatan Pemanfatan Peran Teknologi Informasi Bagi Peserta Didik Lkp Bintang Mulia Batubara," vol. 2, no. 1, pp. 49-52, 2019.

M. Rizaldi, Febri Dristyan, "MERANCANG APLIKASI SMS GATEWAY MENGGUNAKAN GAMMU DAN MODEM ZTE 190 PADA SISWA SMA PANTI BUDAYA KISARAN," J. Pengabdi. Masyrakat Multidisiplin, vol. 4, no. 1, pp. 611, 2020.

M. A. R. Sikumbang, R. Habibi, and S. F. Pane, "Sistem Informasi Absensi Pegawai Menggunakan Metode RAD dan Metode LBS Pada Koordinat Absensi," J. Media Inform. Budidarma, vol. 4, no. 1, p. $\quad 59, \quad 2020, \quad$ doi: 10.30865/mib.v4i1.1445.

C. Mandang, D. C. J. Wuisan, J. G. L. Mandagi, and A. A. Web, "Penerapan Metode RAD dalam Merancang Aplikasi Web Proyek PLN UIP Sulbagut," J. INFORMATICS Eng., vol. 01, no. 02, pp. 49-53, 2020.

M. Christina, F. Dristyan, and S. Informasi, "RANCANG BANGUN SISTEM PAKAR DIAGNOSA PENYAKIT TANAMAN KELAPA MENGGUNAKAN METODE BACKWARD CHAINING," J. Teknol. Komput. dan Sist. Inf., vol. 1, no. 1, 2021. 